\title{
LA MODERACIÓN DE LA CLÁUSULA PENAL EN EL DERECHO ESPAÑOL. CUESTIONES ACTUALES ${ }^{1}$
}

\section{THE MODERATION OF THE CONTRACTUAL PENALTY CLAUSE IN THE SPANISH LAW. CURRENT ISSUES}

\author{
HENAR ÁLVAREZ ÁLVAREZ
}

UNIVERSIDAD DE VALLADOLID

ESPAÑA

"El derecho que es por un costado la prosa, se torna poesía en la lucha por la idea, porque la lucha por el derecho es verdaderamente la poesía del carácter". 


\title{
RESUMEN
}

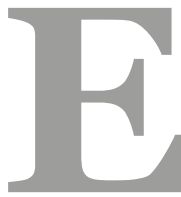

n el presente trabajo se aborda la cuestión de cuándo procede la moderación de la cláusula penal en el ordenamiento jurídico español, teniendo en cuenta la reciente jurisprudencia al respecto. Así, se llega a la conclusión de que solo procede la moderación de la cláusula penal cuando hay cumplimiento parcial de la obligación, pues el supuesto de hecho de la moderación judicial es el cumplimiento parcial o irregular, porque así resulta de lo previsto en el art. 1154 del Código Civil español. Por ello, cuando las partes pactan una pena es para indemnizar el incumplimiento total, y no procederá la moderación cuando la pena se estipuló para indemnizar el cumplimiento parcial o defectuoso. Además, según la jurisprudencia más reciente, procede la moderación de la pena en los casos de incumplimiento parcial del contrato con cláusula penal prevista para el caso de incumplimiento total del resto del precio pendiente de pago en los contratos de compraventa. Además, el Tribunal Supremo español ha descartado que el art. $1154 \mathrm{CC}$ sea aplicable a los supuestos de pena moratoria.

Palabras Clave: cláusula penal; moderación judicial; incumplimiento contractual; garantías de la obligación, derecho de contratos.

\begin{abstract}
Only appropriate judicial discretion of the contractual penalty clause when there is partial obligation compliance, because the assumption of judicial discretion is irregular or partial compliance, because the civil code considers that the parties agreed a penalti to compensate the total failure, while moderation will not proceed when the penalti is stipulated to compensate partially or defective compliance. In addition, according to the most recent jurisprudence, the punishment must be moderated in cases of partial breach of contracts with penalty clauses established for the total breach of the obligation of payment of the defered price. And the Supreme Court has ruled out the 1154 article civil code applicable to cases of penalty moratorium.
\end{abstract}

Keyword: contractual penalty clause; judicial discretion; breach of contract; enforcement guarantees; contract law.

\footnotetext{
${ }^{1}$ El presente trabajo ha sido realizado en el marco del Proyecto de Investigación "La unificación del Derecho Contractual europeo por vía jurisprudencial", financiado por el Ministerio Economía y Competitividad (Ref.: DER2012-35484) español, del que es Investigador principal el Prof. Dr. D. Andrés Domínguez Luelmo, Catedrático de Derecho Civil de la Universidad de Valladolid.
} 


\section{PLANTEAMIENTO INTRODUCTORIO}

En el Derecho español son muchas las sentencias que versan sobre el tema de la cláusula penal, debido a la importante proliferación de este tipo de estipulaciones en el tráfico jurídico. Es cierto que en la actualidad, debido a la crisis económica, y a la multitud de casos en los que las personas se embarcaron en proyectos que no podían asumir atendiendo a sus reales posibilidades económicas, han aumentado exponencialmente los incumplimientos contractuales, lo que provoca problemas de interpretación o de ejecución de las cláusulas penales incorporadas a los contratos para los casos de incumplimiento. Por ello el Tribunal Supremo se ha tenido que pronunciar sobre la facultad de moderación del juez de las cláusulas penales establecidas en un contrato, resolviendo sobre la posible revisión por el tribunal de las cláusulas penales que previamente pactaron las partes.

\section{LA CLASUSULA PENAL. REQUISITOS PARA SU EXIGIBILIDAD}

El Código civil español no contiene una definición de cláusula penal, pero ha sido definida tanto por la doctrina como por la jurisprudencia. Díaz (2011, p.59) partiendo de la dificultad de encontrar un concepto unitario de cláusula penal en el que tengan cabida todas las funciones reconocidas a la misma en el CC, la define como "obligación accesoria que solamente será eficaz cuando se dé el tipo acordado de incumplimiento de la obligación principal y, cuyo objeto es una prestación que satisfaga el interés del acreedor en el modo y medida prefijados por las partes". Otras definiciones similares se han dado en la doctrina: "la pena constituye una obligación, generalmente pecuniaria, de carácter accesorio, que sanciona el incumplimiento o el cumplimiento defectuoso de una obligación contractual" (Arroyo, 2010, p. 1279). Por tanto, la cláusula penal es aquella que se establece en una obligación cuyo incumplimiento se sanciona con ella, sustituyendo a la indemnización de daños y perjuicios y al abono de intereses, salvo pacto en contrario, por lo que no hay que probar la cuantía de los daños sufridos. Es decir, las partes, en virtud del principio de autonomía de la voluntad, en previsión de un incumplimiento contractual, fijan la cuantía de la indemnización, una sanción que es establecida convencionalmente por los interesados, sin que el juez tenga que valorar el daño de acuerdo con el perjuicio sufrido.

Esa sería la cláusula penal sustitutiva, en el sentido de que las partes la fijan como sustitución de la indemnización de daños y perjuicios que en su caso correspondería, cumpliendo una función liquidadora de los daños y perjuicios que el incumplimiento del deudor ocasione al acreedor. Pero también el CC en los art. 1152 y 1153 admite otras modalidades mediando pacto expreso de las partes, en concreto la cláusula penal cumulativa, en el sentido de permitir que el acreedor exija conjuntamente el cumplimiento de la obligación principal o la indemnización 
de daños y perjuicios que el incumplimiento produzca y la satisfacción de la pena, cumpliendo por tanto una función de garantía de cumplimiento de la obligación principal, y también se puede hablar de pena de arrepentimiento o facultativa, en el sentido de dejar al arbitrio del deudor la posibilidad de liberarse del cumplimiento de la obligación pagando la pena, en cuyo caso no estamos ante una cláusula penal propiamente dicha sino más bien ante una obligación facultativa, pues se permite al deudor cumplir su obligación con otra prestación.

En cuanto a las funciones que cumple la cláusula penal, se ha señalado por la doctrina que las principales funciones de la cláusula penal son la punitiva, la resarcitoria y la de garantía. La punitiva en el sentido de que la pena se concibe como una sanción impuesta al deudor infractor; la resarcitoria implica considerar la pena una liquidación convencional y previa de los daños resarcibles; y la de garantía implica considerar la pena como un refuerzo de la obligación principal, siendo esta la función principal que cumple la cláusula penal, pudiendo denominarse también función coercitiva, disuasoria o incluso preventiva (Sanz, 1994, p. 14). Dicho lo cual, en la mayoría de las ocasiones la finalidad de la cláusula penal es asegurar el cumplimiento y por tanto desempeña una función liquidatoria o sustitutoria, en el sentido de que las propias partes convienen en el momento de la celebración del contrato cuáles serán las consecuencias en caso de incumplimiento, por lo que el acreedor no tiene que probar los perjuicios que el incumplimiento le haya ocasionado, no pudiendo tampoco obtener una indemnización mayor. La cuantía de la pena es la pactada, con independencia de que los daños sean menores o mayores, aunque algún sector doctrinal ha considerado que en esos casos cabe indemnización que complemente la cláusula penal pactada, siempre y cuando así se haya pactado (Cabanillas, 1991, p. 158). En contra Carrasco (2013, p. 8464), al señalar que la moderación no puede exceder de la cifra del daño sufrido de modo efectivo por el acreedor. En mi opinión, si las partes han fijado una cláusula penal la pena fijada sustituye a la indemnización por los daños y perjuicios que ocasiona el incumplimiento de la obligación principal, por lo que no se podrá exigir el pago de la pena y además el cumplimiento de la obligación, a no ser que se haya pactado expresamente por las partes como una pena cumulativa en virtud de lo previsto en el segundo párrafo del art. $1153 \mathrm{CC}$.

También se ha señalado que la cláusula penal puede cumplir además de esa función liquidatoria una función coercitiva y cumulativa. Coercitiva en aquellos casos en los que se agrava el resarcimiento, ya que normalmente la pena estipulada supera la cantidad exigible conforme a la responsabilidad contractual, y cumulativa cuando solo en los casos en los que se pacte expresamente el acreedor pueda exigir conjuntamente el cumplimiento de la obligación y la satisfacción de la pena (Marín, 2008).

En cuanto a los requisitos necesarios para la exigibilidad de la pena, es preciso la existencia de una obligación principal válida y de una cláusula penal, el incumplimiento total, parcial o defectuoso de la obligación principal garantizada con la pena, imputabilidad del incumplimiento al deudor (incumplimiento doloso o culposo, no así en los casos de fuerza mayor o caso fortuito), ya que de acuerdo con el art. 1152 CC la pena solo será exigible cuando el 
incumplimiento de la obligación principal sea imputable al deudor y no estemos ante un incumplimiento justificado, que en los supuestos de pena sustitutiva el acreedor haya optado por reclamarla, ya que cuando se haya pactado ese tipo de pena sustitutiva el acreedor puede optar entre exigir el cumplimiento forzoso o la pena, y finalmente que el incumplimiento coincida con la previsión contractual y no con otra, ya que al ser las cláusulas penales una excepción al régimen normal de las obligaciones, son objeto de interpretación restrictiva, en el sentido de que no cabe extender su aplicación a la inobservancia de otras obligaciones no previstas en la cláusula, basándose en el principio de favor debitoris, y así lo ha señalado la jurisprudencia de forma reiterada, lo cual impide su aplicación en supuestos diferentes a los pactados salvo pacto expreso dando vigencia a la cláusula penal. No obstante, para algún sector doctrinal solo tiene sentido tal interpretación de la cláusula penal si se trata de penas punitivas (por una cantidad que excede ostensiblemente la cifra real o probable de daños), o de cláusulas penales cumulativas, que permiten acumular la indemnización de los daños causados realmente con la pena pactada. En el resto de los casos la interpretación restrictiva debería rechazarse (Carrasco, 2013, p. 8454 y 8455).

\section{LA MODERACIÓN JUDICIAL DE LA CLÁUSULA PENAL}

El art. 1154 CC dispone que "El juez modificará equitativamente la pena cuando la obligación principal hubiera sido en parte o irregularmente cumplida por el deudor”. Moderar supone rebajar el exceso de la pena prevista por las partes para el caso de incumplimiento. El TS admite la moderación de cualquier tipo de cláusula penal independientemente de cuál sea su finalidad.

Tanto el art. 1154 CC español como los Códigos de nuestro entorno admiten la posibilidad de que la pena sea moderada, es decir, reducida por los tribunales, siempre y cuando se cumplan los requisitos que prevé el precepto al respecto, concretamente que haya existido un cumplimiento parcial o irregular y que la moderación sea equitativa. Diferente y por ello lo menciono es la regulación de la Compilación de derecho civil de Navarra, pues en la ley 518 se establece que "la pena convenida no podrá ser reducida por el arbitrio judicial", por lo que en el derecho navarro no se admite en ningún caso la facultad moderadora (Fernández, 2012).

Moderar no consiste en prescindir absolutamente de la pena que estipularon las partes en caso de incumplimiento para conceder una indemnización por daños y perjuicios, sino que se parte de la pena que fijaron las partes para un incumplimiento total, y desde la equidad, es decir, el juez no puede moderar a su libre arbitrio o discrecionalidad, se realiza un ajuste cuando se trata de un incumplimiento parcial o irregular, por lo que el resultado obtenido con la moderación debe ser equitativo para ambas partes. La moderación consiste en una disminución o reducción de la pena, pero nunca su supresión absoluta. 
Por tanto la justificación de la moderación de la cláusula penal radica no en rebajar equitativamente una pena excesivamente elevada, en un criterio de proporcionalidad, ya que si el importe de la pena se pactó por las partes en previsión de un incumplimiento total, si ese incumplimiento es parcial, es lógico que la pena se reduzca, proporcionalmente a la satisfacción que haya experimentado el interés del acreedor, a fin de evitar un enriquecimiento injusto si se reclamase en su integridad una pena que excede del daño que se propusieron resarcir quienes la fijaron, aunque en ningún caso se puede suprimir la totalidad de la misma. Se reduce la pena en atención al grado de cumplimiento, a lo que se cumplió, pues la finalidad del art. 1154 CC no reside en si debe rebajarse equitativamente una pena por resultar excesivamente elevada, sino en que las partes, cuando pactaron la pena, pensaron en un incumplimiento total y determinaron la pena en función de esa hipótesis (Cabezuelo, 2014, p. 362 y 363). Además, si la cláusula penal es desproporcionada por causar un desequilibrio contractual que puede ser contrario a la buena fe, la cláusula penal puede ser nula.

Es reiterada la doctrina jurisprudencial que entiende que solo cabe la moderación de la cláusula penal en los casos de incumplimiento parcial, al estar prevista para un incumplimiento total, y también es reiterada la tendencia jurisprudencial en el sentido de no permitir la moderación de la cláusula penal cuando las partes la han previsto para un supuesto de cumplimiento parcial. Diferente es el supuesto en el que la reciente jurisprudencia de nuestro TS considera que sí procede la moderación de la pena en los casos de incumplimiento parcial cuando la cláusula penal está prevista para el caso de incumplimiento total del resto del pago del precio pendiente, tal y como se verá posteriormente.

En principio la moderación podrá aplicarse a todos los tipos de cláusula penal, aunque no parece que tenga cabida en la cláusula penal moratoria ni en la de desistimiento (Díaz, 2011, 103).

Por ello tanto la doctrina como la jurisprudencia se han ocupado de señalar cuáles son los requisitos que tienen que darse para que proceda la moderación. En principio los tribunales pueden moderar la cláusula penal en los casos de incumplimiento parcial con independencia del carácter doloso o negligente del incumplimiento. En efecto, no se tiene en cuenta la existencia de culpa o dolo del deudor en el incumplimiento, pues la moderación de la cláusula penal se realiza conforme al criterio de la equidad, es decir el resultado que se obtiene con la moderación debe ser equitativo para ambas partes. Por tanto, no se puede moderar si la pena convencional se previó por las partes para un supuesto de incumplimiento parcial.

Según la mayoría de la jurisprudencia y de la doctrina la facultad moderadora de los tribunales puede ser aplicada de oficio, aunque alguna sentencia ha entendido que la aplicación del art. 1154 CC debe hacerse mediando petición de la parte interesada. Aunque en algunos supuestos en la práctica resulta que es la parte demandada la que de forma subsidiaria, solicita la moderación planteando que para el caso de que no se estime la pretensión de desestimación íntegra de la demanda y se estime la resolución del contrato por incumplimiento de la parte compradora, se declare la inexistencia de la cláusula penal y subsidiariamente para el caso 
de que se declare la existencia de dicha cláusula, se proceda a la moderación de la misma en los términos en que equitativamente se entienda por el juzgador que se reparan los daños y perjuicios ocasionados a los demandantes (De Amunátegui, 1993, p. 92). No obstante, la doctrina no es unánime al respecto, ya que hay un sector doctrinal que se muestra a favor de que es necesaria solicitud de parte para que se aplique la moderación judicial (Espín, 1997, p. 70 y Díaz-Regañón, 2009, p. 1367), entendiendo que las actuaciones de oficio deben limitarse a la defensa de intereses generales, por lo que es el deudor el que debe solicitar la aplicación del art. 1154 CC alegando la necesidad de reducir el montante debido a la existencia de un cumplimiento parcial. Muestra sus dudas sobre la posibilidad de actuar de oficio Arroyo (2010, p. 1279), y la jurisprudencia también se haya dividida al respecto.

Ahora bien, la facultad moderadora que recoge el art. 1154 CC así como la decisión sobre la improcedencia de hacer uso de tal facultad, son facultades que no pueden ni deben ser alteradas en vía casacional cuando se basan en una valoración lógica y racional asentada en bases fácticas incontrovertibles (STS de 1 de octubre de 2010 y 12 de marzo de 2012, entre otras). Por tanto la facultad mediadora del art. 1154 CC no es susceptible de recurso de casación. La posible moderación corresponde al tribunal de instancia, no siendo recurrible en casación, pero sí la apreciación sobre la existencia o no de cumplimiento. Solo estaría sujeto a casación los parámetros utilizados por el juzgador para fijar la pena y el juicio sobre el supuesto de hecho del art. 1154 CC (Carrasco, 2013, p. 8465). Y ello como consecuencia de la aplicación del principio general de la interpretación de los contratos según el cual es el tribunal de instancia el que tiene la función de interpretación, la cual debe prevalecer y no puede ser revisada en casación en la medida en que se ajuste a los hechos probados. Solo cuando la moderación de la pena sea ilógica, irracional o arbitraria, cabrá la posibilidad de revisarla en casación. No obstante lo anterior, algún autor ha considerado que el juicio de equidad sí podrá ser revisable en casación en los casos en los que por ejemplo, se reduzca la pena a una cantidad ridícula, desproporcionada con el grado de insatisfacción del interés del acreedor, cuando se contraríe el principio de conmutatividad de las prestaciones, cuando haya enriquecimiento injusto, cuando exista prohibición de fijar una cantidad inferior a los daños realmente producidos o en los casos de responsabilidad por dolo (Mas, 1995, p. 98).

Ahora bien, en la actualidad se considera mayoritariamente por la doctrina que la moderación de la cláusula penal no puede entenderse como una simple facultad del juez, sino que el art. 1154 CC es un precepto imperativo que constituye un deber de actuación para el juez, por lo que cuando el cumplimiento de la obligación haya sido parcial, irregular o defectuoso, el juez tiene la obligación de moderar la pena prevista por las partes para el caso de incumplimiento total. No obstante, algunas sentencias no muy recientes afirmaron que el art. 1154 CC no obliga al juez y éste puede prescindir de moderar la pena si así le parece más equitativa (Cabanillas, 1991, p. 160). En este sentido, un sector minoritario de la doctrina se ha manifestado sosteniendo que el art. 1154 CC tiene carácter dispositivo fundamentándolo sobre todo en el 
principio de justicia rogada y en el carácter dispositivo del derecho civil, por lo que no solo se trataría de una facultad y no un deber del juez, sino que además el juez no puede apreciar de oficio la aplicación del art. 1154 CC, y tendrá que ser la parte interesada quien solicite la aplicación del precepto al juez (Mas, 1995, p. 75).

Pero como digo la jurisprudencia más reciente así como la mayoría de la doctrina se muestran partidarios a la idea de considerar que el deber del juez de modificar la pena tiene carácter imperativo, debido al tenor literal del art. $1154 \mathrm{CC}$, se contiene un mandato imperativo, artículo que sufrió una variación respecto de su precedente de García Goyena de 1851, donde se decía "el juez puede modificar equitativamente la pena estipulada cuando la obligación principal se hubiese cumplido en parte y no en el todo" (Marín, 2008 y De Amunátegui, 1993, p. 88). Hasta tal punto se considera que la moderación del art. 1154 CC tiene carácter imperativo que incluso se ha defendido que las partes no podrán mediante pacto excluir la aplicación de la facultad moderadora de los jueces que recoge el precepto (Guilarte, 1999, p. 140). En contra se manifiestan otros autores al entender que la moderación del art. 1154 CC es imperativa para el juez pero ello no es óbice para que las partes puedan acordar válidamente la no aplicación del precepto (Mas, 1995, p. 77 y Díaz, 2011, p. 117 y 118). Además, se ha señalado que esta aparente contraposición entre el art. $1154 \mathrm{CC}$ y el Proyecto de CC de 1851 no es tal. En los Códigos europeos de nuestro entorno, donde se contempla la facultad moderadora del juez como una facultad del juez, como algo potestativo, el cual podrá a su arbitrio moderar o no en cada caso, a diferencia del tenor literal del art. 1154 CC que parece que obliga a moderar la pena de forma imperativa, en realidad la redacción tanto del art. 1154 CC como de los códigos europeos y del Proyecto de CC de 1851 el espíritu es el mismo en todos ellos, pues en todos los textos la facultad moderadora es el encomendarle al juez un juicio de equidad, aunque no a su libre arbitrio o discrecionalidad, respecto de la cuantía de la pena pactada, en los casos en los que exista un incumplimiento parcial o irregular (Díaz, 2013, p. 78 y 79).

De lo que no hay duda es que el juez cuando modera la pena debe hacerlo basándose en criterios de equidad, reduciendo la pena en proporción al perjuicio evitado por el cumplimiento parcial o irregular. Es decir, cuando el juez constata que hay un incumplimiento parcial o irregular de la obligación principal por parte del deudor, la moderación será equitativa, siendo la equidad el criterio que va a determinar el alcance de la moderación de la pena. Es decir, la moderación de la cláusula penal debe hacerse sin que quede desnaturalizada la función que las partes le hayan asignado a la cláusula penal, evitándose que la indemnización que reciba el acreedor sea excesiva y contraria a la equidad y a la buena fe. A mayor abundamiento, aunque haya habido un incumplimiento parcial o irregular, solo habrá obligación de moderar cuando dicha moderación resulte equitativa. En la práctica tal circunstancia operará en la mayoría de los casos, ya que ante un cumplimiento parcial la moderación será casi siempre equitativa, ya que se presume que la pena se pactó para el incumplimiento absoluto, pero en los casos en los que así no sea no se debe moderar la pena (Díaz, 2013, p. 78 y 79). 
Ahora bien, puede haber supuestos en los que lo más equitativo sea no moderar, es decir, no siempre lo más equitativo es reducir el importe de la pena y así lo ha mantenido el TS en determinados supuestos (Espín, 1997, p. 71 y 72).

Cuestión distinta es si la cláusula penal puede moderarse con base en la equidad y el equilibrio de las prestaciones. En principio el TS ha considerado que no cabe que el juez modere las cláusulas excesivas o desproporcionadas al tener que respetarse la función que cumple la cláusula penal y la voluntad de los contratantes en aplicación de los principios de la autonomía de la voluntad y de la fuerza obligatoria de los contratos, además de evitar la inseguridad jurídica. Es decir, si la pena es desproporcionada o abusiva, tal y como tiene declarado el TS en multitud de ocasiones, es irrelevante a efectos de la moderación, siendo inaplicable el art. $1154 \mathrm{CC}$ a los supuestos de incumplimiento total. Por tanto, la equidad solo puede ir referida a la cuantía en que se realiza la moderación, pero no a los supuestos en los que se ha de practicar la misma. La jurisprudencia del TS al respecto es constante en señalar que no cabe la moderación por razones de equidad, incluso aunque la pena sea desproporcionada o abusiva, ya que la cuantía de la misma es libremente pactada por las partes.

En este sentido, resulta claro que nuestro art. $1154 \mathrm{CC}$ no recoge la posibilidad de reducir la pena manifiestamente excesiva, sino que la moderación puede tener lugar, siempre que sea conforme a la equidad, cuando exista un incumplimiento parcial o irregular. En efecto en nuestro derecho no existe una norma que expresamente permita a diferencia de lo que ocurre en otros ordenamientos jurídicos extranjeros la revisión judicial de las cláusulas penales excesivas. Sin embargo, en otros ordenamientos jurídicos de nuestro entorno, así como en el art. 9:509 de los PECL sí que se permite al juez disminuir la pena si ésta es manifiestamente excesiva. ¿Por qué nuestro CC es tan riguroso al ser el único de nuestro entorno que no establece la equidad como motivo para la reducción de la cláusula penal pactada? Básicamente por la aplicación del principio de autonomía de la voluntad y por el de que el contrato es ley entre las partes. No obstante, parte de la doctrina se pronuncia a favor de la revisión judicial de la pena por razones de equidad, por lo que se podría corregir las cláusulas penales abusivas o desproporcionadas incluso cuando hay incumplimiento total, debido a que la desproporción existente entre la pena y el daño sufrido es el presupuesto objetivo de moderación judicial de la pena (Marín, 2008). Pero para revisar las penas abusivas en nuestro derecho los autores no pueden acudir al art. 1154 CC ni a su interpretación analógica, pues las partes han pactado la pena para el caso de incumplimiento total, y esa es doctrina constante en nuestra jurisprudencia, por lo que acuden a otros argumentos, a otras vías que ofrece nuestro ordenamiento jurídico para revisar las penas exorbitantes o excesivas, como es la aplicación del principio general de la buena fe contractual del art. $1258 \mathrm{CC}$, el respeto a la moral como límite a la autonomía de la voluntad del art. $1255 \mathrm{CC}$, la aplicación del art. $1103 \mathrm{CC}$ para reducir las penas excesivas siempre y cuando el incumplimiento de la obligación principal se hubiera debido a la culpa o cuando hubiera existido mala fe del acreedor, o el abuso del derecho recogido en el art. 7.2 CC 
(Mas, 1995, p. 216). A favor de la revisión de la cláusula penal por excesiva o desproporcionada se manifiesta De Castro (2009, p. 130), fundamentándolo en la voluntad de las partes manifestada en el contrato y su interpretación, en el sentido de buscar la intención o finalidad de las partes a la hora de establecer la cláusula penal, así como la actitud de las partes en la celebración y ejecución del contrato, pues el dolo o culpa grave y la mala fe en el incumplimiento no puede tener iguales consecuencias que la simple negligencia y la buena fe, debiéndose tener en cuenta también la actitud en algunos casos abusiva del acreedor tanto en la elaboración del contrato como a lo largo de la relación obligatoria.

Y esa es la tendencia legislativa de revisión judicial de la pena por razones de equidad no solo en el resto de los ordenamientos jurídicos europeos sino también en nuestro Derecho, pues la Propuesta de la Comisión General de Codificación de Anteproyecto de Ley de Modernización del Derecho de Obligaciones y Contratos del año 2009 modifica sustancialmente el régimen de la cláusula penal, en el sentido de que admite la moderación judicial de la pena por razones de equidad en el art. 1150 cuyo tenor literal es el siguiente: "El Juez modificará equitativamente las penas convencionales manifiestamente excesivas y las indemnizaciones desproporcionadas en relación con el daño efectivamente sufrido” Marín, 2009). Por tanto nuestro legislador ya está pensando en moderar las cláusulas penales excesivas. En este sentido la doctrina mayoritaria se muestra partidaria de moderar la pena por razones de equidad cuando exista una reforma legal previa, por lo que en los casos de excesividad o carácter irrisorio de la pena no puede tenerse en cuenta en los casos de incumplimiento total, ya que solo cabe la moderación si el incumplimiento es parcial (Espín, 1997, p. 86).

También se ha esgrimido muy excepcionalmente por la jurisprudencia y parte de la doctrina el art. 1103 CC para moderar la pena por el juez aunque no haya incumplimiento parcial, sino total, siempre y cuando no haya dolo o mala fe, sino negligencia, pues este precepto permite al juez moderar la responsabilidad procedente de negligencia, no así en los casos de deudor doloso o de mala fe. Este sector de la doctrina que se muestra partidario de aplicar este artículo para moderar la pena, entiende que a pesar de existir un incumplimiento total, cuando hay una desproporción entre los daños sufridos y la pena fijada anticipadamente, es decir, cuando la pena resulta excesiva, se puede acudir a la facultad general de moderación de los jueces y tribunales del art. $1103 \mathrm{CC}$, ya que de acuerdo con el principio de equivalencia de las prestaciones se podría llegar a producir un enriquecimiento injusto y por ende un desequilibrio si se aplica la pena tal y como las partes lo habían pactado. En cuanto al criterio que debe seguir según este sector doctrinal el tribunal para aplicar el art 1103 CC a la hora de determinar cuándo una cláusula penal debe considerarse excesiva, podrán utilizar criterios como el efectivo perjuicio sufrido por el acreedor, los daños previsibles al tiempo de la conclusión del contrato, los intereses de las partes, la naturaleza y clase de contrato y las circunstancias en las que se ha realizado, y los motivos del incumplimiento, por lo que sería aplicable el art. 1103 CC para moderar la cláusula penal no solo en los casos de incumplimiento parcial sino también 
cuando dicho incumplimiento es total (Guilarte, 1999, 137 y Hernández, 2013, p. 173).

De hecho, los ordenamientos jurídicos de nuestro entorno así como los proyectos de reforma legislativa de nuestro ordenamiento jurídico son mucho más flexibles y permiten la moderación de las cláusulas penales en cualquier caso, tanto si el incumplimiento es parcial como si es total a los efectos de evitar un enriquecimiento injusto. De hecho, tal y como manifiesta Bercovitz (2014), incluso el TS se ha pronunciado en alguna ocasión en el sentido de moderar las penas previstas por las partes al resultar excesivas en aplicación del art. $1103 \mathrm{CC}$, al considerar que en los casos en los que la cláusula penal pactada sea exorbitante o manifiestamente excesiva, podrá ser rebajada y por tanto moderada. Aunque se trata de un sector minoritario aún en nuestra doctrina, Díaz $(2011,128)$ aboga por la posibilidad de moderar la cláusula penal aplicando el art. $1103 \mathrm{CC}$ en los casos de penas exorbitantes.

En contra de aplicar el art. $1103 \mathrm{CC}$ a las penas liquidatorias se pronuncia De Amunátegui (1993, p. 117 y 118), al entender que no se puede aplicar el art. 1103 CC en los casos de cláusula penal liquidatoria, pues en estos supuestos la pena sustituye la indemnización, sin tener en cuenta el valor de los daños, aunque sí será aplicable en los casos de pena cumulativa, al sumarse una cantidad como pena a la indemnización de los daños.

Pero, ¿qué ocurrirá si la pena pactada es inferior al daño realmente producido? ¿Y si la pena fuera irrisoria o incluso no existe daño? En nuestro Derecho no existe una norma que de modo expreso permita la revisión judicial de las cláusulas penales irrisorias, al igual que tampoco lo hay para las excesivas. El motivo de plantearse esta cuestión no es otro que si la pena es irrisoria, no se cumple la función asignada a la cláusula penal, cual es su función de garantía, pues en esos casos la pena se encuentra muy por debajo de los daños reales. La doctrina por ello se ha manifestado en el sentido de plantearse si las penas irrisorias son verdaderas cláusulas penales, pues con ellas parece que se potencia el incumplimiento del deudor, por lo que en realidad nos encontramos ante una cláusula limitativa de la responsabilidad (Más, 1995, p. 266).

En un principio, siguiendo el tenor literal de la regulación de la cláusula penal en nuestro CC cabría pensar que el juez no puede modificar la cantidad pactada, por lo que el deudor deberá pagar la pena fijada íntegramente en caso de incumplimiento. De la misma manera que no cabría la reducción de penas excesivas o elevadas, tampoco podría procederse al aumento de las penas irrisorias, pues las partes libremente han teniendo en cuenta una serie de circunstancias a la hora de valorar la pena fijada, por lo que debe respetarse el principio de autonomía de la voluntad así como el de la fuerza obligatoria de los contratos. En efecto, la función liquidatoria o sustitutiva que cumple la cláusula penal supone una liquidación anticipada que realizan las partes de los posibles daños y perjuicios que puedan derivarse del incumplimiento del contrato, por lo que no es necesario ni probar su existencia ni la cuantía de los daños. Solamente podrá cambiarse la cuantía de la pena pactada en los casos en los que los tribunales procedan a su moderación cuando se den los requisitos legales previstos para ello.

Ahora bien, si la pena queda insuficiente y por debajo de los daños y perjuicios, beneficia al 
sujeto incumplidor, por lo que tanto la doctrina como la jurisprudencia mediante la aplicación de la cláusula rebus sic stantibus, es decir, el cambio trascendente no previsible de las circunstancias bajo las que se pactó la cláusula penal, considera que en esos casos la cláusula penal ha quedado sin efecto por lo que para evitar un resultado injusto no se aplicaría el art. 1152 CC sino que se entiende que en aplicación de la cláusula rebus sic stantibus se podrán alterar los términos en que fue concertado el contrato ante la alteración sobrevenida de las circunstancias, pudiéndose incluso optar por la no aplicación de la cláusula penal notablemente inferior a los daños sufridos basándose únicamente en la equidad (De Amunátegui, 1993, p. 74).

No obstante, también se ha considerado que en un sistema en el que se admite la pena cumulativa sin especial correlación entre pena y daño previsible el juez puede interpretar el contrato restrictivamente para no aplicar la cláusula penal y sustituirla por la indemnización ordinaria. Pero el juez al realizar su labor interpretadora debe tener en cuenta qué conceptos de daño han tenido en cuenta las partes a la hora de establecerla pena, por si lo hubieran querido establecer como una indemnización mínima. Ahora bien, si hubiera habido dolo o culpa grave en el incumplimiento, el acreedor debería recibir una indemnización plena. No obstante, es conveniente que las partes a la hora de fijar la pena sean muy precisos porque los tribunales en la mayoría de las ocasiones la utilizan en su vertiente sustitutiva sin tener en cuenta el daño efectivamente producido (De Castro, 2009, p. 139 y 140). Por ello nuestros tribunales en ocasiones han concedido la indemnización por mayor daño por distintas vías, buscando un resultado más equitativo, lo cual resulta criticable, pues si se trata de alcanzar un resultado acorde con criterios de justicia material, la generalización de este tipo de decisiones judiciales llevaría aparejada la pérdida de valor de la figura de la cláusula penal, pues se introduce en su posible utilización la inseguridad respecto de cómo será entendida por los Tribunales (Espín, 1997, p. 117).

\section{SUPUESTOS EXCLUÍDOS DE LA MODERACIÓN}

El art. $1154 \mathrm{CC}$ establece de manera imperativa que los tribunales podrán moderar la pena en los supuestos de incumplimiento parcial o defectuoso, debiendo el juez moderar aunque no sea solicitado por ninguna de las partes. Ahora bien, existen unos supuestos en los que no cabe la facultad moderadora, y son los siguientes:

- Cuando el incumplimiento es total, pues la facultad moderadora de los tribunales solo puede realizarse cuando el incumplimiento es parcial o irregular de la obligación principal, y ello con independencia de que la pena sea excesiva o no por no corresponderse con los daños efectivamente producidos. No obstante, hay un sector de la doctrina que defiende la aplicación del art. 1154 CC y por tanto la moderación judicial de la pena en los supuestos de incumplimiento total, basándose en la equidad, entendiendo que lo que determina la aplicación del 
precepto no es la existencia de un cumplimiento parcial o irregular, en relación al incumplimiento previsto en la cláusula como determinante de la exigencia de la pena, sino la existencia de una desproporción en la pena atendiendo las circunstancias concretas del caso. En realidad no se trataría de aplicar el art. $1154 \mathrm{CC}$, sino que en aquellos casos en los que dicho precepto no puede ser aplicado, por ejemplo en los casos de incumplimiento total, se podrá acudir al art. 1103 CC para poder moderar así la pena. Normalmente la desproporción se dará en los casos de cumplimiento parcial, pero no todo cumplimiento parcial da lugar a la moderación de la pena, ni tampoco está prohibida la moderación en casos de incumplimiento total, por lo que debe proceder la moderación judicial de la pena si es desproporcionada, abusiva o excesiva, con independencia de que el incumplimiento sea total o parcial (Rodríguez, p. 582).

- Cuando la cláusula penal está prevista para un determinado incumplimiento parcial, no puede aplicarse la facultad moderadora del art. 1154 CC si se produce precisamente es incumplimiento parcial, pues la moderación solo puede tener lugar cuando se hubiera incumplido en parte la total obligación para la que la pena fue prevista, pues el juez no puede moderar la pena cuando se produce el tipo de incumplimiento previsto por las partes. Ello en consonancia con el principio de autonomía de la voluntad (art. 1255 CC) y con el efecto vinculante de los pactos creados "pacta sunt servanda" (art. $1091 \mathrm{CC}$ ).

En efecto, no se puede moderar una cláusula penal convenida por las partes al amparo del art. 1154 CC cuando se trate de un cumplimiento parcial o irregular del deudor cuando precisamente la pena pactada se haya previsto para sancionar el incumplimiento parcial o deficiente producido. Así, si la cláusula penal está establecida para un determinado incumplimiento, aunque sea parcial, no puede aplicarse la facultad moderadora del art. 1154 CC si se produce exactamente ese incumplimiento previsto. Así, la moderación puede tener lugar solo si se ha cumplido en parte o irregularmente la obligación para cuyo incumplimiento total la pena se estableció:

- Cuando la cláusula penal se ha previsto para los supuestos de mora. En efecto, la jurisprudencia no admite la moderación de la cláusula penal en los casos de retraso en el cumplimiento, ya que la demora en el cumplimiento es incompatible con los conceptos de incumplimiento parcial o irregular, únicos casos para los que se halla instituida la facultad moderadora de los tribunales. Siempre que se dé el retraso se produce un incumplimiento total y por ello no cabe la moderación ex art. 1154 CC. Así, si se produce el retraso, la pena se paga íntegramente, aunque se trate de una pena excesiva, ya que la pena estaba prevista precisamente para el retraso en la ejecución de la prestación debida, a pesar de ser el incumplimiento tardío un supuesto de cumplimiento irregular. Sin embargo, en alguna ocasión excepcionalmente el TS sí que ha moderado la pena moratoria por entender que el retraso no ha sido generalizado sino parcial, por referirse a parte del objeto de la prestación (Sanz, 1994, p. 101 y 102 y Díaz, 2011, p. 250).

- Cuando la cláusula penal es excesiva. Tal y como se ha visto en el epígrafe anterior, el juez no puede moderar la cláusula penal exclusivamente por considerarla excesiva o desorbitada, ya 
que la cuantía de la misma es libremente pactada por las partes, a diferencia de lo que ocurre en los ordenamientos jurídicos europeos, en los que se prevé la posible moderación judicial si la pena es manifiestamente excesiva. Esta es la interpretación mayoritaria que se realiza del art. 1154 CC tanto por la doctrina como por la jurisprudencia, pues se trata de un precepto que no contempla la moderación de las penas excesivas o desproporcionadas, siendo necesario en todo caso que se modificara el CC y se permitiera esta moderación. No obstante, cuando la pena a posteriori resulta muy desproporcionada respecto del daño producido, parte de la doctrina propone a través de diversas vías correcciones en el sentido de limitar su alcance atendiendo a la justicia del caso concreto por razones de equidad, basándose en los art. 1103, 1258 o 7.2 CC, al entender que la imposición de penas excesivas es contrario a la buena fe contractual, o incluso porque habría un enriquecimiento injusto o un abuso de derecho, entendido en el sentido de que tal abuso responde al ejercicio de un derecho que rebasa naturalmente los límites en que está especificado en su contenido o conjunto de facultades (Sanz, 1994, 96 y De Castro, 2009, 564). Ahora bien, si la fijación de la pena convencional es libre, las partes tienen libertad de acuerdo con el principio de autonomía de la voluntad y con la regla pacta sunt servanda para valorar el incumplimiento, y no puede ser contrario a la buena fe reclamar todo el importe, salvo claro está, en materia de consumidores, pues en este ámbito sí que se puede declarar la nulidad de la cláusula penal por abusiva y moderar así los derechos y obligaciones de las partes, considerándose que la cláusula penal es cláusula abusiva en el ámbito de las condiciones generales de la contratación y de los contratos de adhesión (Quesada, 2003 y Más, 1995, p. 241).

No obstante, de acuerdo con la jurisprudencia del TS cuando la cláusula penal es declarada nula, no se puede moderar, es decir, al tenerla por no puesta, no es posible reducirla. Según esta doctrina que aplica el TS, no es posible que los tribunales moderen una indemnización considerada abusiva, reduciéndola al límite de los daños efectivamente producidos o en general a la cuantía que procedería indemnizar conforme a las normas generales, si no existiera la cláusula penal. Así lo ha considerado en la reciente Sentencia de 11 de marzo de 2014, en la que se limita a establecer que cuando la cláusula penal es nula no se puede moderar (Plana, 2014). Tal nulidad de la cláusula abusiva tendrá lugar cuando fije una cantidad superior al daño previsible medio, resultando desproporcionada, alejada con mucho del daño real indemnizable.

Recordemos que parte de la doctrina se muestra partidaria de interpretar los art. 1103 y $1154 \mathrm{CC}$ de acuerdo con la realidad social de nuestro tiempo (art. $3 \mathrm{CC}$ ) en el sentido de que los tribunales puedan moderar las cláusulas penales que resulten excesivas en cualquier tipo de incumplimiento, ya sea total o parcial, aplicando el art. 1103 CC en base a la equidad para moderar. De hecho ya alguna sentencia del TS incluso en los supuestos de incumplimiento total ha procedido a moderar la pena al considerarla excesiva, aunque no sobre la base del art. 1154 CC sino entendiendo que aunque el incumplimiento es total en realidad se trata de un cumplimiento parcial, para así poder aplicar el art. $1154 \mathrm{CC}$, o bien aplicando el art. $1103 \mathrm{CC}$ de forma explícita pues este precepto no excluye como el art. $1154 \mathrm{CC}$ su aplicación a los casos de 
incumplimiento total, o incluso utilizando el argumento de la interpretación restrictiva de las cláusulas penales (Bercovitz, 2014, Díaz, 2011, p. 30).

\section{MODERACIÓN DE LA CLÁUSULA PENAL EN LOS CASOS DE INCUMPLIMIENTO PARCIAL}

Según la interpretación tradicional del art. 1154 CC, la moderación judicial solo se admite en los supuestos de cumplimiento parcial o irregular de la obligación principal, es decir, cuando el supuesto que se da en la realidad no coincide totalmente con el previsto por las partes. Ahora bien, la moderación de la pena en caso de cumplimiento parcial de la obligación principal supone mantener y respetar la voluntad contractual, pues se adapta la pena prevista por las partes para el supuesto de incumplimiento total al cumplimiento parcial o irregular realmente producido, es decir, se reduce la pena en proporción al cumplimiento realizado, pues de aplicarse automáticamente la cláusula penal cuanto mayor hubiera sido el grado de cumplimiento del deudor mayor sería la pena que sufriría, lo cual no tiene mucho sentido.

No obstante, en nuestro ordenamiento jurídico la pena no tiene que coincidir necesariamente con el importe de los daños causados efectivamente por el incumplimiento y las partes tienen plena libertad para fijar la cuantía de la pena.

Cuando la cláusula penal está prevista para un determinado incumplimiento parcial o irregular, no puede aplicarse la facultad moderadora del art. 1154 CC si efectivamente se produce ese incumplimiento, y así lo ha mantenido el TS de manera reiterada. Es decir, no se trataría de un cumplimiento parcial o irregular, sino de un incumplimiento absoluto de la prestación a la que se añade la cláusula penal.

En efecto, se ha visto anteriormente cuales son los requisitos que deben darse para que los tribunales puedan moderar la pena, así como los supuestos en los que esta facultad no puede ser ejercitada. Ha quedado constatado que el TS cuando aplica la cláusula penal no la modera si se ha previsto para el cumplimiento total, y también para el caso de cumplimiento parcial si la cláusula precisamente se previó por las partes para ese tipo de incumplimiento, con independencia de si por parte del contratante incumplidor ha existido un comportamiento negligente o doloso.

Por tanto no puede acudirse a la moderación cuando el incumplimiento sea total, el cual debe ser apreciado no respecto de las circunstancias del contrato globalmente considerado, sino en cuanto al concreto cumplimiento de la obligación garantizada con la pena. Por ello, según la jurisprudencia del TS, si la pena está prevista para una concreta obligación y es precisamente esta la que se incumple totalmente, no cabe la moderación, y también se considera como incumplimiento total por la jurisprudencia los casos de pago del precio aplazado, des- 
contando el importe de la entrega inicial (De Amunátegui, 2014).

Últimamente el TS ha dado un giro en su doctrina tradicional al considerar que si se pagan parte de las cantidades aplazadas, se trata de un supuesto de cumplimiento parcial o irregular de las obligaciones aplazadas, por lo que se aplica el art. $1154 \mathrm{CC}$ en el sentido de entender que se trata de un incumplimiento parcial y que por tanto procede la moderación. Esta nueva línea jurisprudencial del TS se vislumbra en las STS de 4 de octubre de 2007, de 7 de mayo de 2012, y de 11 de noviembre de 2014, al entender que procede la moderación de la pena prevista para garantizar el cumplimiento del resto del precio cuando se procede al pago de algunas cantidades aplazadas.

El TS para apoyar la procedencia de la moderación de la cláusula penal en estos supuestos considera que los contratantes estipularon la cláusula penal para un incumplimiento total para el caso de incumplimiento de parte del pago del precio. En el momento de celebración del contrato los compradores abonaron una cantidad de dinero, por lo que los compradores ya no podían incumplir totalmente su obligación, por lo que nunca podría ser íntegramente efectiva la cuantía prevista para la pena. Es decir, el supuesto que se toma como referencia no es la totalidad del precio de la compraventa, sino la de la parte del precio aplazado. Y aunque la cláusula penal se hubiera configurado como un supuesto de incumplimiento parcial, se habría dado un cumplimiento parcial de lo que habían previsto las partes en la cláusula penal, es decir, un incumplimiento más leve del previsto para que opere la cláusula penal. Es por ello por lo que el TS entiende que se puede moderar la pena.

En el mismo sentido, el TS valora la infracción del impago de un plazo en relación con el grado de incumplimiento de la obligación, para evitar que la pena se incremente proporcionalmente al grado de cumplimiento alcanzado. De hecho, es jurisprudencia reiterada la de la moderación de este tipo de cláusulas. Ahora bien, en otros casos, el Alto Tribunal ha considerado que al vendedor se le ocasionan una serie de daños si se compara el valor del precio que no se restituye con el goce de la cosa que ha experimentado el comprador, por lo que en estos casos el TS entiende que no cabe aplicar la facultad moderadora porque la cláusula está prevista expresamente para un incumplimiento parcial, basándose en que las partes cuando pactaron la pena pensaron en el caso de un incumplimiento total y en función de esa hipótesis evaluaron la pena, porque cuando se previó para un incumplimiento parcial, la cláusula se rige por lo previsto por las partes (STS de 14 de junio de 2006.

De esta manera, lo fundamental a la hora de moderar la pena es dilucidar si existe o no cumplimiento irregular de la obligación que en concreto se garantiza mediante la cláusula penal, con independencia de que exista un mayor o menor cumplimiento de otras obligaciones que surjan del contrato. Se tiene que incurrir o no en la irregularidad sancionada con la pena y no en otro tipo de incumplimiento.

$\mathrm{El}$ art. $1154 \mathrm{CC}$ está previsto para el incumplimiento de la obligación, pero también para los casos de retraso en el cumplimiento (cláusulas penales moratorias) o cuando se deja de pa- 
gar un plazo (cláusulas penales comisorias). En estos últimos dos casos el art. $1154 \mathrm{CC}$ se aplica adaptándolo al concreto supuesto de hecho previsto en la cláusula penal, por lo que el juez tiene que valorar el grado de cumplimiento o irregularidad desde el punto de vista de lo pactado por las partes. Si la infracción de esa concreta conducta es total no cabe la moderación, pero sí si es parcial o irregular, es decir cuando solo se paga una parte del plazo acordado, como en el supuesto de la sentencia que comento.

Es decir, en los casos de cumplimiento parcial de pago del precio, la moderación judicial procede a los efectos de dividir la pena porque se ha dividido a su vez el cumplimiento de la obligación. De hecho, el TS suele optar por la moderación para evitar la notoria desproporción que se podría derivar de la no moderación de la pena produciéndose en ese caso un enriquecimiento injusto del acreedor.

Por tanto, la jurisprudencia más reciente del TS considera que es procedente la moderación de la pena cuando se ha acordado por las partes que si se deja de abonar algún plazo se resuelva el contrato de compraventa, ya que en atención precisamente a que se ha pagado parte del precio, cabe la moderación de la pena, pues existe cumplimiento parcial. Si hay cumplimiento parcial del cumplimiento parcial, es decir, si se ha cumplido en parte y se ha pagado parte de las cantidades aplazadas, se considera que es un cumplimiento parcial y que por tanto cabe la moderación de la pena.

\section{A MODO DE CONCLUSIÓN}

El TS se ha pronunciado en multitud de ocasiones sobre la facultad moderadora del art. 1154 CC, en concreto, sobre la exigibilidad de la pena, su moderación, la imposibilidad de moderar cuando nos encontramos ante un incumplimiento total, así como el control del uso de la facultad de moderar. Esta moderación de la cláusula penal supone modificar la cuantía pactada como pena por las partes para el caso de incumplimiento. Se ha visto cuál ha sido la doctrina reiterada al respecto del TS sobre estas cuestiones, y sobre todo si cabe extender la moderación en los casos no de incumplimientos parciales o irregulares sino también a los totales, porque a priori el tenor literal del art. $1154 \mathrm{CC}$ parece que está vetando tal posibilidad. De esta manera, el juez no puede moderar la pena si la obligación principal se incumplió totalmente ni tampoco si el incumplimiento parcial era el precisamente previsto en la cláusula penal.

Sobre la moderación de la pena han recaído una gran cantidad de sentencias, debido a que esta cuestión ha provocado una gran litigiosidad en nuestros tribunales y en la mayoría de las ocasiones el TS considera que es claro que el juez puede moderar la cláusula penal cuando ésta esté prevista para un incumplimiento de mayor entidad al incumplimiento efectuado por el deudor. Así, el art. 1154 CC impone al juez el deber de modificar la pena cuando haya existido un 
cumplimiento parcial o irregular de la obligación principal, no pudiendo moderar tampoco en los casos en los que la pena convencional se previó para los supuestos de incumplimiento parcial. Por tanto el juez solo puede moderar la pena cuando la cláusula penal prevea un incumplimiento de mayor entidad al incumplimiento efectivo del deudor. Máxime si se tiene en cuenta que con la moderación de la pena se pretende que el acreedor no obtenga un beneficio injustificadamente desproporcionado ante el incumplimiento del deudor. Por ello el juez, en aplicación del art. 1154 CC "modificará equitativamente la pena”, en el sentido de reducir la pena de acuerdo con su criterio discrecional, que no arbitrario, según las circunstancias de cada caso.

\section{REFERENCIAS BIBLIOGRÁFICAS}

De Amunátegui Rodríguez, Cristina (1993). La función liquidatoria de la cláusula penal en la jurisprudencia del Tribunal Supremo, Bosch, Barcelona.

De Amunátegui Rodríguez, Cristina (2014). "Comentario a la STS de 23 de septiembre de 2013”, en Cuadernos Civitas de Jurisprudencia Civil, ${ }^{0} 95$.

Arroyo I Amayuelas, Esther (2010). "Comentario al art. 1152 del CC", en Comentarios al Código Civil, Dir. DOMÍNGUEZ LUELMO, Lex Nova, Valladolid.

Bercovitz Rodríguez-Cano, Rodrigo (2014). "Comentario a la STS de 30 de abril de 2013", en Cuadernos Civitas de Jurisprudencia Civil, nº 95.

Cabanillas Sánchez, Antonio (1991). "Comentario al art. 1152 del CC", en Comentario del Código Civil, Tomo II, Ministerio de Justicia.

Cabezuelo Arenas, Ana Laura (2014). "Comentario a la STS de 21 de junio de 2013", en Cuadernos Civitas de Jurisprudencia Civil, $\mathrm{n}^{0} 94$.

Carrasco Perera, Ángel (2013). “Comentario al art. 1152 del CC”, en Comentarios al Código Civil, Tomo VI (Arts. 1043 a 1264), Dir. BERCOVITZ RODRÍGUEZ-CANO, Tirant lo Blanch, Valencia.

De Castro Vítores, Germán (2009). La cláusula penal ante la armonización del derecho contractual europeo, Dykinson, Madrid. 
Díaz Alabart, Silvia (2011). La cláusula penal, Reus, Madrid.

Díaz-Regañón García-Alcalá, Calixto, (2009). "Comentario al art. 1154 del CC”, en Comentarios al Código Civil, Coord. BERCOVITZ RODRÍGUEZ-CANO, Aranzadi, $3^{\text {a }}$ ed., 2009.

Espín Alba, Isabel (1997). La cláusula penal: especial referencia a la moderación de la pena, Marcial Pons.

Fernández Martínez, Juan Manuel (2012). "La moderación judicial de la cláusula penal”, en Revista Aranzadi Doctrinal, $n^{o} 1$.

Guilarte Martín-Calero, Cristina (1999). La moderación de la culpa por los tribunales. Estudio doctrinal y jurisprudencial, Lex Nova.

Hernández Díaz-Ambrona, María Dolores (2013). “Comentario a la STS de 23 de octubre de 2012, CCJC, $\mathrm{n}^{0} 93$.

Marín García, Ignacio (2008). “Cláusula penal: la facultad moderadora del juez”, en InDret.

Marín García, Ignacio (2009). "La cláusula penal en la Propuesta de Modernización del Código civil en materia de Obligaciones y Contratos”, en InDret.

Más Badía, María Dolores (1995). La revisión judicial de las cláusulas penales, Tirant lo Blanch, Valencia.

Plana Arnaldos, María del Carmen (2014). "Comentario a la STS de 11 de marzo de 2014", en Cuadernos Civitas de Jurisprudencia Civil, nº 96.

Quesada González, María Corona (2003). "Estudio de la Jurisprudencia del Tribunal Supremo sobre la pena convencional”, en Aranzadi Civil, $\mathrm{n}^{\circ} 14$.

Rodríguez Tapia, José Miguel. "Sobre la cláusula penal en el Código civil”, en Anuario de Derecho Civil, T. XLVI.

Sanz Viola, Ana (1994). La cláusula penal en el Código Civil, J. M. Bosch Editor, Barcelona. 


\section{CURRICULUM VITAE}

\section{Henar Álvarez Álvarez}

Licenciada en Derecho por la Universidad de Valladolid en junio de 1999.

Doctora en Derecho por la Universidad de Valladolid con la calificación de sobresaliente cum laude por unanimidad, el 13 de octubre de 2003.

Fiscal sustituta en la Audiencia Provincial de Segovia.

Profesora titular de Derecho Civil en la Universidad de Valladolid (España), julio 2009.

halvarez@der.uva.es 